\title{
Dinámicas configuraciones étnicas y renovaciones culturales inéditas. El caso de la más reciente evangelización protestante entre los indígenas guambianos en Colombia
}

\author{
Juan Diego Demera V.*
}

Resumen. Este trabajo de investigación presenta y analiza los procesos de imposición, transferencia y mudanza de los preceptos misionales protestantes entre los indígenas guambianos de Colombia. Parte de la idea del cambio cultural para mostrar las dinámicas configuraciones de la etnicidad y la religiosidad guambianas, a través de la inclusión de los procesos de choque, localización y resistencia. A partir del análisis de narrativas orales y de la etnografía, el estudio contempla los elementos más significativos de la conversión religiosa, del cambio y la memoria ritual.

Palabras clave: cambio cultural, memoria ritual, etnicidad, protestantismo

\begin{abstract}
A bstract. This article analyzes the process of imposition, transference and change of protestant missionary precepts within the indigenous community of Guambia in Cauca, Colombia. Based on the concept of cultural change, the objective of this article is to demostrate the dynamic configuration of Guambian ethnicity and religiousness through the processes of struggle, establishment and resistance. Through the analysis of oral narrative and ethnography, the research focuses on the most significant elements of religious conversion, change, and ritual memory.
\end{abstract}

Keywords: cultural change, ritual mermory, ethnicity, protestantism

* Investigador del Instituto Colombiano para el Estudio de las Religiones, ICER. Actualmente es candidato al Master en Sociedades Contemporáneas Comparadas. Europa-A mérica Latina del Iheal- Universidad París III, con el apoyo del Programa A Iban, Programa deBecas deA Ito N ivel dela Unión Europea para América Latina, Beca NE05M 060386CO. Correo electrónico: juandiegodemera@yahoo.com 


\section{Introducción}

Desde los inicios de la antropología, su objetivo inicial y el pilar fundamental de su interés académico fuela descripción y el análisis dela otredad y de la multiplicidad humana, así como la ampliación de nuestras representaciones del mundo. El antropólogo se enfrentó así a sociedades radical mente diferentes a él, a su sociedad y a su cultura. Sin embargo, al mismo tiempo, llegó a ellas a través de contactos previos entre esas sociedades lejanas y los ejércitos, los agentes y los comerciantes de las naciones, gobiernos y culturas que comprendían al antropólogo y a la antropología. Ese contacto entre sujetos diversos y la posterior ampliación de las zonas de frontera se prolongaría hasta nuestros días. A cada nueva mirada del antropólogo, estas relaciones implicaban dinámicas configuraciones culturales, disímiles búsquedas rituales e inéditas posturas identitarias.

La mirada antropológica, dispuesta a revelar los resquicios de la diferencia, silenció por muchos años el cambio, la adaptación y el choque cultural. Al mismo tiempo, la emergencia de los análisis etnográficos de la cultura contemporánea permitió que la antropología se alejara con frecuencia de sociedades étnicas que consideraba arcaicas, y tal vez profusamente abordadas por las aproximaciones clásicas. Este trabajo se teje en contravía a estos dos presupuestos. De una parte, aborda la contemporaneidad cultural de una comunidad étnica andina, profundamente atravesada por las ofertas, las búsquedas y las luchas simbólicas de la modernidad religiosa. Por otra parte, examina la rica pluralidad de sentidos, representaciones y experiencias que implican la compleja recreación de elementos propios y ajenos, novedosos y compartidos, a la luz de dinámicos vínculos étnicos y emergentes identidades culturales.

El resguardo indígena de Guambía, en el noroccidente del departamento del Cauca, Colombia, tiene una población aproximada de 12 mil guambianos. Ellos, tras un largo proceso de dominación que incluyó, entre otros, el pago del terraje ${ }^{1}$ y la ocupación de terrenos

${ }^{1}$ Actividad económica mediante la cual los terratenientes permitían de manera temporal la ocupación o explotación de pequeños terrenos a familias guambianas 
ancestrales por la población “blanca” y "mestiza” de la católica y conservadora capital caucana, forjaron importantes procesos de recomposición y movilización social a través de la recuperación del territorio, la autoridad y la cultura a partir de 1980.

No obstanteestos procesos de unidad, su vecindad con el universo no indígena y los permanentes diálogos con la cultura de la región han permitido la emergencia de nuevos movimientos e ideas religiosas que van recomponiendo el paisaje social y cultural de este grupo andino. Dehecho, en este pequeño espacio ubicado en los andes centrales deColombia existen nuevemovimientos religiosos asociados al protestantismo en todas sus gamas, tendencias y variantes. Los primeros embates del protestantismo estuvieron en manos de empresas misioneras norteamericanas apenas entrado el siglo xx, y sólo hasta finales deestesiglo, otras iglesias, más cercanas a los pentecostal ismos y últimamente a las variantes pentecostales de creación latinoamericana, empiezan a llegar o a ser invitados.

Desde esta perspectiva, es evidente que la etnicidad, es decir, la formación histórica einacabada de grupos diferenciados social, cultural y políticamente (Cardoso, 1992), se construyeen medio dezonas y situaciones de frontera y contacto. Para el caso de este grupo étnico caucano, su ubicación andina y los permanentes intercambios entre sus resguardos ${ }^{2}$ y las sociedades que los comprendían, hicieron delas misiones protestantes uno más de los múltiples factores que intervenían en el diálogo entre un "nosotros" y un "otros", cada vez menos absolutos.

Dehecho, aunquela adopción del protestantismo entreguambianos y paeces semantuvo relativamenteajena al movimiento político y a la emergencia de la articulación étnica que hizo posible el movimiento

a cambio de trabajo gratuito en las haciendas. Estas últimas habían sido expropiadas al Resguardo Indígena de Guambía mediante diversos procesos.

${ }^{2}$ El resguardo indígena es una entidad territorial especial en Colombia. En el medio andino generalmente comprenden extensiones menores que hacen parte de otras entidades territoriales no indígenas. Cuenta con relativa autonomía política a través de la figura del "Cabildo", elemento del orden político colonial transformado en símbolo esencial de la autoridad propia. 
indígena de la década de los años 1980 en Colombia (Rappaport, 1984; Gros, 2000), esto fue posible sólo después de intensas luchas simbólicas y culturales (Demera, 2004). Además, los embates de las transformaciones y las manipulaciones culturales no obedecieron claramente a los designios políticos más colectivos, ni quedaron inmóviles ante la aparición de nuevos movimientos, nuevas inquietudes y acuerdos.

A través del recurso a la etnografía y a la antropología histórica, este texto presenta los principales embates culturales de la adopción y la circulación dela más recienteola deevangel ización entrelos indígenas guambianos. Esta práctica misionera, que comprende todo el siglo xx, se afincó en un espacio cultural profundamente denso, y a través de esos intercambios, imposiciones y transformaciones, recreó la religiosidad, la etnicidad y las relaciones de fuerza entre las prácticas de evangelización dentro de los guambianos.

El estudio del cual parteeste artículo puso énfasis en las narrativas orales de los guambianos creyentes, quienes, a través de su memoria y su interpretación del fenómeno, definieron los elementos significativos a la experiencia religiosa y cultural vivida. Como parte de estos elementos, haremos hincapiéen el impacto dela experiencia misionera en la medicina y las formas de curar, en la sabiduría y el consejo, y en la cultura ritual. El trabajo de campo, realizado discontinuamente entre los años 2001 y 2002, nos permitió enfrentarnos a una comunidad abierta y en aras de reafinar los vínculos étnicos en medio de un agitado presentey de unos intereses culturales inacabados.

La cotidianidad del resguardo incluía en varias vías la participación de espacios de religiosidad muy variables, en algunos casos tangenciales, comprometidos o enfrentados. De hecho, la presencia deun antropólogo desconocido y un tanto sospechoso permitió la elaboración de sendos discursos que dieron forma a las expectativas y a los compromisos delos guambianos involucrados, quienes difícilmente hubieran logrado entablar diálogos positivos en medio delas pugnas doctrinales y las pertenencias institucionales. De fondo, varios discursos estaban entrelazadosy sólo la profundidad dela narración oral, de la biografía social y de la subjetividad, permitió decantar las diferencias etnográficas más evidentes o las divisiones institucionales instauradas. 
Las narrativas del antropólogo (Rosaldo, 1991), la mirada delos efectos de "nuestra sociedad" sobre "sus sociedades" y la escritura deestas diferencias, similitudes, desfases e incomprensiones Ilenaron los diarios de campo y estas hojas. No obstante, estas conclusiones están repletas de diál ogos y denarrativas ajenas que permitieron descentrar en variossentidos el problema del cambio y la memoriaindígena. Si en un principio el análisis deestos procesos hacía parte del repertorio deuna "antropología de salvamento", una alerta por la desaparición de las costumbres y tradiciones, poco a poco tomaron forma otros elementos quellenaron deprofundidad histórica y dediversificación antropológica tanto los cambios como los mecanismos deresistencia cultural aplicados.

Los cursos simbólicos siempre representarán un campo fértil tanto para la observación como para la experimentación vivencial, al hacer partedel choquequesoporta la inmersión y la experiencia etnográfica. La ampliación de estos referentes propios y subjetivos la encontramos en las narrativas de los actores: monjas, curas, pastores, líderes protestantes, creyentes, infieles, simpatizantes y críticos, en medio de un espacio geográfico limitado pero densamenteocupado, a través de la pertenencia étnica, de la continua circulación del pasado y de la preocupación por el futuro.

En definitiva, la actividad misionera es una actividad contemporánea y permanente. Lejos del imaginario antropológico de sociedades estáticas, resueltamente ajenas a nuestras sociedades, la política, y en especial la cultura, se muestran como campos en los cuales el guambiano encuentra mayores y más dinámicos intereses decambio, renovación y transformación.

Como en otras oportunidades, los componentes educativos, médicos y rituales se imponen como medios fundamentales de la conversión religiosa y cultural. N o obstante, estos elementos se transforman y se manipulan en medio de contextos sociales y culturales precisos, dentro de los cual es seejercen imposiciones, búsquedas y negociaciones frecuentes. Al mismo tiempo, y a pesar de que la penetración de ideas y prácticas religiosas se ejerce en un solo sentido, las imposiciones son muchas veces parciales, y en ellas se exponen, con toda la dinámica y la creatividad posibles, elementos que ligan, hacen memoria y reconstruyen los referentes deidentificación cultural y social. 
De esta manera, la etnicidad va más allá de los meros compromisos políticos. Este grupo se identifica y actúa colectivamente a partir de una compleja dinámica, dentro de la cual se inscriben y se localizan un número incierto deprácticas y procesos queevocan un pasado común, una idea de un "nosotros" y una diferencia tangible construida a través del tiempo. Esa diferenciación colectiva toma ejes de la participación activa de prácticas, ideas y rituales que tejen la novedad, el cambio y las resistencias culturales, muchas veces demaneras impensadas. La religiosidad hace partedeestos elementos. En ella, en sus cambios y en sus maniobras, se encuentran la complejidad del interés en el cambio, la reconstrucción, la recreación y la memoria.

Como el ementos que sobrepasan la intención de este artículo y de nuestra investigación, pensamos en el importante papel desempeñado por los jóvenes indígenas, ansiosos al cambio, a los relevos generacionales y a las creaciones rebeldes, en las nuevas y futuras adopciones religiosas. Además, es un aspecto sobresaliente el papel que tiene la religiosidad andina como un elemento cargado de pugnas simbólicas, a la cual tal vez recurren permanentemente las disidencias étnicas. Estos y otros elementos quedarán como parte de las futuras intromisiones antropológicas.

Este trabajo presenta al gunos de los elementos más significativos dela experiencia cultural renovada por el protestantismo guambiano. Presentamos al gunas delas referencias tradicional es guambianas más sugestivas en términos de su posición cercana, lejana o contrapuesta al protestantismo, en campos como la curación y la medicina, la concepción del saber, la educación y el consejo, y la pertenencia a un universo ritual y cotidiano. En todos los casos, el objetivo es plantear algunas de las posiciones, las distancias, las alteraciones ejercidas y las ideas novedosas surgidas de la adopción, la imposición, el choque y la transformación tanto de los intereses misioneros como de las prácticas guambianas.

\section{Predicar, curar y soñar}

La medicina tradicional guambiana está basada en un sistema de intermediación, ejercido por un chamán o mèrèpik. Estos médicos 
aprenden y aplican los remedios o "frescos" solicitados por medio de sueños y visiones. A través de ellos, conocen la enfermedad y aprenden cómo contrarrestarla. Las prácticas más comunes son la utilización de diversas plantas medicinales, aguardiente, cigarrillos y coca, e incluso el agua bendita y las estampillas católicas.

No obstante, la medicina tradicional guambiana actúa en situaciones que desbordan el campo restringido dela salud física personal y atraen cada uno de los espacios y tiempos de la vida y la actuación de los guambianos. Los trabajos del mèrèpik incluyen una gama variada de actividades muy relacionadas. Espantan la enfermedad, física y moral, "refrescan" el nuevo cabildo, fortalecen la cementera, Ilaman el verano o el invierno, despiden a los muertos y revelan el mejor lugar para construir una nueva casa. En este último caso, pueden determinar si existe un sierpi, un espíritu de agua, ojos de agua o caminos bajo la tierra en donde se construirá la casa, y preparar plantas para habitarla, o plantas vivas para que cuiden de ella (Vasco, Dagua y A randa, 1998).

La idea y la práctica del refresco tradicional, un riego que da vía al equilibrio, está directamente relacionada con el Pishimisak, principal ser de la creencia guambiana, ${ }^{3}$ frecuentemente asociado a un pequeño niño que tiene los pies al revés y anda por los páramos. Él es quien da sueños a los médicos y a todos los guambianos. Al Ilamarlo, "juertiándolo" con aguardiente, baja delas lagunas y páramos, y ayuda al mèrèpik a liberar la enfermedad del cuerpo del enfermo, del cabildo o de la tierra. El fresco es ofrecido al Pishimisak, en relación con las lagunas, las cordilleras, las plantas y el agua. Junto al aguardiente, el tabaco, la coca y algunos bastones de poder bendecidos católicamente, el ritual le da apertura al mèrèpik para que realice su trabajo.

3 “Dueño del agua, del humano y de todo". Enseña a cultivar, da sueños de aprendizaje y enferma, "él dio orden de cómo vivir y dio poder por medio del sueño para curar las enfermedades...Quien interpreta es el mèrèpik, el que sabe ver, un sabio propio. Kallim siempre aparece entre nubes o entre chispiadero del páramo. Pishimisak es dos, es un par, pakatè; es Kallim, quees macho, y es propio Pishimisak. Es la unicidad" (Vasco, Dagua y Aranda, 1998: 37-38). 
Esta manera de actuar frente a las enfermedades y los males adquiridos toma expresiones particulares y síntomas de la enfermedad y las situaciones problemáticas del individuo. Estas expresiones de dolor y angustia, así como las maneras de contrarrestar y restablecer el equilibrio, forman parte de las concepciones diferenciadas de salud-enfermedad, étnicamente construidas. Tal como cuenta Eulogio Tunubalá (2002), un mèrèpik guambiano: “Cuando una persona es asustada, al guno que va a morir, la sombra aparece, y ése por la mera oración no pasa, ponen a hacer oración y no pasa". Es necesario "sentir", a través del cuerpo y el sueño del mèrèpik, las características y refrescos útiles para que pase ese "espíritu maligno", para "fresquiarlo" o para que el espíritu de un muerto descanse y quede contento. Este tipo de síntomas, un sierpi o una sombra, su proceder y su tratamiento, enraízan un complejo cognoscitivo propiamente guambiano. Así lo narra taita Abelino Dagua (2002), para el caso de una enfermedad de sombra:

Las plantas tienen una sombra, y esa sombra de día no se camina, de día está quieta junto a la planta, a las ocho o nueve de la noche está la planta sola y el espíritu va rodeando cualquier parte como si fuera una mariposa o un ave, hasta donde quiera ir se va. Y eso es lo que trae la enfermedad, cada una viene con diferentes formas deanimal es, y eseespíritu ahuyenta a mi espíritu, quiere coger, y cuando coge se masca y ahí le queja a uno el dolor. Cuando les queja entonces hay otro espíritu que es águila y esa águila le saca la lengua, pero no sesacala lengua sino el espíritu mismo; entonces cuando se grita el búho, el enfermo dice que muere. $\mathrm{Mi}$ espíritu como que quedó allí, pero no, uno quedó con la planta, el otro queda en el entierro y el otro queda como a volver, ése es el que viene cada año en tiempo de las ofrendas, ése no está muerto sino que camina como ambulante en la tierra misma.

La conjugación de ideas ancestrales con rituales contemporáneos que atraen permanentemente las referencias católicas, fue ignorada 0 tolerada por el clero y la dirigencia católica. El catolicismo cedió antes 
de contener el uso de los mèrèpik y deotras prácticas ritual es creativas arraigadas en el resguardo, vivas en las costumbres locales y en el entramado de pensamientos y prácticas culturales.

Por supuesto, negarsea reproducir prácticas médicas queincluyen todo el universo normativo y la cotidianidad dela vida guambiana, el pensamiento, las ceremonias y las actividades diarias, seconstituyeron como uno de los intereses prioritarios de los misioneros protestantes. Obedeciendo a las disposiciones bíblicas y los objetivos misioneros, uno delos temas clave dentro dela producción de nuevos indígenas cristianos fue la anulación de las formas indígenas de medicina. Aunque su extirpación es relativa, los desafíos propuestos por los misioneros fueron significativos.

Para los misioneros y los pastores protestantes, el fortalecimiento del uso de la medicina occidental y la promoción dela disciplina cristiana, ofrecida como medio para adquirir dones de sanación divina, fueron elementos centrales de su actividad. Desde un principio, los misioneros extranjeros ofrecieron apoyo, medicina y capacitación en salud a los indígenas mediante institutos y cartillas bíblicas. No obstante, el escaso prestigio de la medicina occidental en el resguardo y las tradiciones culturales previas hicieron más efectivas las mediaciones carismáticas que vincularon al pastor con la sanación.

Tal como afirman Jean y John Comaroff (1997: 323), la combinación depredicación y sanación ha sido el mejor método deintroducción de la cristiandad. Los pastores, al igual que los mèrèpik, seencargaron de la reproducción social del grupo, proveyendo el bienestar médico, el consejo y la renovación de la misticidad. Los misioneros y pastores actuales conservaron así la estrecha relación entre sacerdote y doctor (Comaroff y Comaroff, 1997: 323).

Por medio de la experimentación dentro del resguardo, el misionero inglés Edwin Dennis logró convertirse en uno de los médicos más utilizados por protestantes y católicos. Lejos de ser pasiva, su actividad se vinculó a la medicina practicada dentro del resguardo. Dennis utilizó una medicina al terativa que atenuaba los medicamentos, utilizaba masajes y plantas. De esta manera logró, al mismo tiempo, desplazar el uso de al gunos médicos tradicionales y servir de contrapeso a la medicina occidental. El éxito de este misionero-médico radicó en 
complementar la predicación por el bienestar cristiano y la crítica evangélica a la vida guambiana, con el auxilio de prácticas médicas ajenas tanto a las costumbres tradicionales como a la medicina occidental.

La creatividad del médico inglés cesó por los problemas políticos del ministerio evangélico dentro de losindígenas. Pero tan pronto salió del resguardo, un nuevo médico evangélico surgió en la vereda de PuenteReal. I gnacio M orales, al igual queDennis, iba en contra delos médicos tradicionales y utilizaba otro tipo de prácticas médicas no convencionales. Este médico tampoco tenía título de medicina pero gozaba de una gran diferencia que lo hacía una versión mejorada del misionero inglés, era soñado para curar. Hace treinta y cinco años, Ignacio M orales aprendió el oficio de la medicina en una seriede sueños, tal como es costumbreentrelos médicos tradicionales guambianos. A rasgos generales, el primero de sus sueños ocurrió de esta manera:

Yo veía así claritico como si fuera de día, estaba todo despejado, todo azul, y yo iba caminando por una calleen Silvia cuando de pronto yo veía una estrella muy luminosa. Yo seguía caminando y un niño quevenía detrás mío me decía quemire la estrella, que al cáncela, que usted puede. Y yo empezaba a tratar de cogerla pero escapaba, hasta que por fin la agarréy la cogí entre las manos, y aparecieron unas herramientas. El niño se puso a decir que las cogiera y que yo desde ese momento iba a poder curar a cualquier persona y a cualquier enfermedad que yo quisiera, y que estas cosas eran enviadas por Jesucristo directamente, eran cosas divinas, no eran cosas terrenales. A sí seguí soñando y fui aprendiendo yo solo. Después le dije al pastor y miramos que en la Biblia también hay unas historias con los sueños que se revelan (Ignacio Morales, comunicación personal, 2002).

El aprender por medio de sueños y el estar destinado a ejercer un oficio determinado, de acuerdo con las condiciones marcadas por $\mathrm{el}$ sueño, son características de la participación social guambiana. Aunque el sueño de los mèrèpik se manifiesta cada vez que van a curar y este médico sólo aprendió en ellos, este recurso envolvió la práctica evangélica de la medicina de don Ignacio Morales. Esto implicaría 
el comienzo de una creativa práctica de la medicina evangélica a la que pronto se sumaría el ejercicio de la sanidad divina.

Indudablemente, la promesa de sanidad divina es hoy la mayor influencia en torno a la adopción del protestantismo. De hecho, la escasa adscripción a los Testigos de Jehová puede pensarse como fruto de la carencia de este tipo de promesas médicas. En la década de los noventa tomó importancia la introducción del pensamiento evangélico más restrictivo. Jairo Santa ( $s / f: 1$ ) dice:

Satanás tiene un sinnúmero de siervos camuflados con títulos muy sugestivos como yerbateros, espiritistas, profesores, magos, adivinos, homeópatas, parapsicólogos o gurúes, encargados de engañar y esclavizar a muchas personas, las personas dentro y fuera de la Iglesia deben ser advertidas de esta treta satánica [...] pues todo espíritu que no confiesa que Jesucristo ha venido en carne no es de Dios.

Este pensamiento fue introducido al resguardo por los nuevos movimientos religiosos, entre los que se encuentran los grupos pentecostales, Bettesda y el Movimiento Misionero Mundial. Para estos grupos, la restricción a las creativas prácticas médicas locales y el ejercicio desu propia actividad curativa mediantela sanación divina son actividades centrales. En ella, el ritual evangélico, realizado en el culto y dirigido casi absolutamente por el pastor, permite obtener la curación de las enfermedades y la extirpación de los "demonios" que causan la enfermedad o la tristeza. Más que ver al pastor como un ser que interviene en un acto divino colectivo, los creyentes asumen la sanación como una actividad pensada y favorecida personalmente, por medio del trabajo del pastor y su comunicación sagrada.

Indudablemente, la práctica médica ejercida en manos del pastor cristiano ha encontrado escuchas y practicantes cada vez más numerosos entre los guambianos. No obstante, su trabajo halló recepción sólo a través de la creación de numerosos puentes y de la exaltación de referencias más o menos conocidas en torno a los preceptos guambianos de salud-enfermedad. Estos posibles vínculos se refieren a la consecución de dones especiales mediante los cuales los pastores o los 
mèrèpik, mediadores delo sagrado y lo humano, ven, sueñan y actúan de manera mística en un enfermo y en una enfermedad. En las visiones de los creyentes pentecostales y detodos aquellos quecuran y son curados en medio de un culto, aparecen estrellas, animales y otros personajes o seres que intervienen en la lucha contra las enfermedades. En estas iglesias, los males son vistos como espíritus que enferman a los creyentes, a los cuales también es necesario "refrescar", pero ahora con "la sangre de Cristo".

Como puede observarse, la concepción de la salud y la enfermedad propia de los grupos protestantes y pentecostales encontró algunas referencias equiparables a las concepciones místicas de la tradición guambiana. Las visiones, los dones y la utilización de personajes especiales para sanar están presentes en ambas prácticas rituales. Asimismo, las enfermedades son una mezcla de males físicos, morales y sociales que actúan por medio de seres y sombras que merodean al enfermo.

Dehecho, al gunos deestos médicos-pastores, especial menteaqueIlos que son guambianos, también han tendido puentes y han creado particulares formas de "medicina cristiana". Para Juan Tunubalá, ${ }^{4}$ por ejemplo, las enfermedades son espíritus malignos que circulan por la noche, una concepción muy similar a la expresada en el relato tradicional de taita Abelino Dagua. Además, dentro de sus "tratamientos", la tradición guambiana ha estado continuamente presente. Sueños como los quetuvo el médico Ignacio M orales oJuan Tunubalá, son parte del universo explicativo guambiano. Dentro de ellos, la aparición de los ángeles niños, algunas veces vestidos de guambianos, recuerdan el papel del sueño quebrinda el Pishimisak, asociado generalmente a figuras infantiles que imparten y generan poder. Esos sueños son utilizados como herramienta que sustenta sus propios dones de sanación.

De la misma manera, la iglesia Dios es Amor, liderada por Juan Tunubalá, ha buscado asociar su religión a la productividad de las

${ }^{4}$ Pastor de un movimiento religioso que parte de la iglesia pentecostal brasileña Dios es Amor, pero que ahora está buscando un nuevo nombre y un sentido guambiano. 
cosechas, el descanso de los muertos, la limpieza de la casa nueva y la lucha contra los seres malignos que circulan por la noche. Y lo ha he cho mediante el uso delas lagunas y páramos, los bastones de poder y el "fresco" con agua consagrada en una copa católica o en el culto evangélico. Estos lugares, prácticas y personajes cumplen funciones parecidas a las del médico tradicional, pero ahora operan a través de pastores o creyentes. Actúan por medio de agua y aceite ungidos y han sido convertidos en motivo de proselitismo religioso. ${ }^{5}$

\section{Sabiduría, educación y consejo}

Desde un principio, la educación católica implicó cambios abruptos en la cotidianidad guambiana, desdela introducción del pensamiento religioso hasta el uso de los zapatos (Vasco, 1993) y la prohibición a hablar la lengua guambiana dentro de sus colegios. Las arbitrarias relaciones de poder blanco-indígena se trasladaban directamentea la escuela como medio para poder ejercer la transformación "necesaria" del indígena. Incluso moldeó las actitudes violentas delos guambianos frente a la introducción del protestantismo.

La educación en manos de los religiosos tomó importancia dentro del resguardo, y cuando en 1960 el gobierno decidió instaurar el primer colegio secular, la educación religiosa, católica y protestante, ya estaba funcionando. $Y$ aunque no siempre hayan sido efectivos en las prácticas académicas o en la formación técnica impartida, su impacto fue transcendental en las prácticas de socialización y desarrollo del pensamiento, de expansión y dominio intercultural (Jimeno y Triana, 1985: 202).

Las escuelas religiosas, católicas y protestantes, han sido un elemento central en la práctica misionera y aún hoy convocan el interés de las familias guambianas. Este interés, tanto de maestros como de creyentes y no creyentes, tiene que ver con la reproducción en Guambía de una particular idea de educación. Ésta es vista como la adquisición

${ }^{5}$ La tradición guambiana no hace públicos los dones y sueños, sólo los utiliza para la circulación de la vida ritual y de la cotidianidad. 
de nuevas y ajenas costumbres que no tienen mayor relación con la sabiduría y la formación social e intelectual guambiana. Tal como cuenta mama Bárbara Muelas, al gunos de los padres deciden enviar sus hijos a las escuelas evangélicas o católicas porque en el Colegio Agropecuario Guambiano, queabandera los procesos etnoeducativos en el resguardo, "no enseñan ni a rezar". De esta manera, continuamente se piensa el campo educativo como un espacio para la pérdida cultural y no para el tráfico de culturas y conocimientos.

La escuel a evangélica, en manos dela Alianza Cristianay Misionera, se presenta como un tipo de formación basada en la fuerte restricción de las actividades humanas. Infundeel respeto y la disciplina, la memorización de versículos y la realización de cantos y rondas religiosos. Los padres de familia y maestros cristianos exigen la prohibición dela enseñanza de bailes, música y otras tradiciones guambianas, aunque fomentan el cuidado del vestido, la participación en el cabildo y la lengua propia.

Indudablemente, en estas escuelas se cuestionan la mayoría delos referentes culturales sobre los cuales circula la cotidianidad étnica. Los referentes construidos ponen énfasis en la exteriorización de la pertenencia y en la diferenciación del "otro" a través de elementos políticamente construidos: el vestido, la lengua y el cabildo (Gros, 1999). La pertenencia étnica se exponea través de nociones muy bien definidas, construidas por el movimiento indígena frente al Estado y al "otro" no indígena, pero pierden devista la pluralidad de sentidos, representaciones y experiencias de la cotidianidad étnica.

En cuanto al manejo del saber, los al umnos cristianos se destacan por su manejo de la lectura y la oratoria literal, pero son más débiles en el manejo de la oralidad y más difíciles de introducir en lo propio. No obstante, el desarrollo de su experiencia educativa fuera de las instituciones cristianas reafirma una profunda brecha entre el compromiso religioso de niños, jóvenes y adultos creyentes. La juventud está marcada por ese desprendimiento de las actividades restrictivas del protestantismo.

La actividad educativa de las monjas, tras la introducción protestante y la inclusión de trabajadoras misioneras guambianas, se transformó en una política más amabley menos restrictiva frente a la cultura 
(Jimeno y Triana, 1985: 208). Impulsó la etnoeducación y las prácticas indígenas, y se convirtió en la "línea blanda" de las religiones dentro del resguardo. Además, la socialización de niños y jóvenes en la vida y pulso del resguardo indígena, y su paso por escuelas seculares o católicas, permiten la circulación y apropiación de nuevos discursos y actitudes que reincorporan vivencias repelidas por el protestantismo.

La existencia del resguardo como una unidad sociocultural que dinamiza constantemente la etnicidad y la participación étnica, y la importancia de la educación secular, así como las palabras de los mayores y compañeros guambianos, contrarrestan frecuentemente los discursos religiosos. Tal como acusan los nuevos pastores y profesores cristianos, "cuando son pequeños, empiezan muy bien, pero cuando van a la adolescencia, cuando van a otros colegios, cambian de actitud, se van haciendo lo que el mundo hace, crecen y se van olvidando" (Antonio Pillimué, entrevista, 2002). Sin duda, estos elementos han sido una constante y dinámica forma de resistencia, entendida en términos de mecanismos que permiten tomar distancia de los preceptos y propuestas misionales iniciales, aunque no podamos hablar de una absoluta oposición de procederes o de posiciones antagónicas.

Es interesante que este papel que cumple la cultura y la educación secular no tenga las mismas consecuencias dentro de la educación de los hijos de pastores mestizos. A lgunos de ellos estudian en los colegios guambianos y en ocasiones, junto a los pastores, aprenden delos creyentes la lengua, el himno y múltiples aspectos de la cultura guambiana. Este conocimiento se convierte sólo en una herramienta de penetración y adoctrinamiento o es concebido como un exotismo local, susceptible a cambios cristianos. La idea de cambiar al otro y la social ización fuera del resguardo al ientan la incomprensión de prácticas y costumbres guambianas y la adopción de restrictivos discursos y doctrinas protestantes. A esto se debe que hoy los creyentes busquen y acojan pastores foráneos, un medio para encontrar rigor y distancia de la cultura. Además, por esto funcionaban entre los indígenas los internados católicos, y en Guambía, los pastores formados en los institutos bíblicos debían salir de sus comunidades a recibir capacitación y socialización occidental. 
Sin embargo, el papel de los mayores en la orientación de los jóvenes estudiantes permitió que muchos de los estudiantes cristianos y no cristianos se convirtieran en líderes guambianos y promovieran la participación política y el rescate de las tradiciones y costumbres guambianas. Muchos de ellos aprovecharon la exigente formación en escritura y lectura de sus escuelas y escribieron cartas y manifiestos políticos para defender su vida y su cotidianidad al lado de taitas y mayores.

A hora bien, más allá de la formación cristiana y las escuelas dominicales, hoy los adultos y jóvenes guambianos adquieren la palabra que mantiene sus vidas alejadas del alcohol, la violencia y los vicios "del mundo" a través del culto evangélico. El consejo para losjóvenes protestantes se ha desplazado del fogón de la casa y de la voz del taita, a la amplitud de una sala y al imaginario del pastor. Algunos de los consejeros han sido líderes o ancianos evangélicos guambianos, cargos que permitieron la continuidad del consejo de manos de la experiencia y el ejercicio común. Para otros, la mayoría, es sólo la palabra del pastor evangélico o simplemente la Biblia lo que ha de enseñarles, y para esto existen múltiples manuales y sencillas orientaciones dogmáticas. Otros pocos, en especial los pentecostales de Dios es A mor, seguirán aprendiendo a través de los sueños cristianos, pues según afirma Fabio Yalanda: “Dios enseña por medio de sueños", o efectivamente, los guambianos siguen aprendiendo de esa manera.

\section{La cultura ritual}

La cultura guambiana se presenta hoy definitivamente imbricada en la participación católica. Si bien ésta inhibió en forma constanteel desarrollo delas prácticas ancestrales, no logró suprimirlas, las hizo parte de prácticas sincréticas que abrieron múltiples espacios adyacentes. Los ritos de paso secontrolan por medio dela ritualidad católica, pues los bautizos, las primeras comuniones, los matrimonios y entierros implican la participación del ceremonial católico, pero al mismo tiempo convocan a los músicos guambianos, recrean los lazos de socialización propios y recurren a vestidos y sombreros tradicionales. 
Sin duda, la música, el baile, la muerte y el vestido entretejen cultura y pensamiento guambiano, buscan constantemente espacios de coexistencia y participación, y entran al campo de la transformación, la recreación y el choque.

La música guambiana, las flautas y los tambores encierran un universo normativo y cognoscitivo. Las doce piezas principales de la música guambiana sirven alas actividades más importantes dela vida individual y colectiva. Cuatro de ellas están destinadas al bautismo y anuncian que "un nuevo patrón o patrona ha llegado y quellevará el nombre dela abuela o el abuelo", otras cuatro son para el matrimonio y las restantes para el padrino y el dueño dela casa. Entretodas, como piensa taita A belino Dagua, desde las seis de la tarde a las seis de la mañana, "dan vida".

La música da vida porquetienerelación con los árboles, con el agua, con la vista, el oído, el habla y el pensamiento propio. La música guambiana se relaciona con los órganos de los sentidos porque seencarga de mantener despiertos y escuchando a los asistentes a la fiesta para que nunca se duerman. Los instrumentos tienen relación con el árbol porque "Ios músicos han recogido en las flautas el murmulleo de los árboles cuando a veces parecen que ¡siiiilban!, a veces que ¡lloooran!, y otras veces como que ¡chiiiillan!" (Entrevista a Abelino Dagua, 2002). Las flautas son un par, como el padrino y la madrina o la ahijada y el ahijado. Era el instrumento de Pishimisak para llamar a mingar a los guambianos y aún se utiliza para llamar a que la gente acompañe. El tambor también hace acompañar, pero es la fuerza del baile y de la vida de los danzantes, pues es el espíritu del aguacero que viene gritando, avisando y llamando la atención, convocando dulcemente la memoria y el futuro a través de un acto ritual.

La música acompaña en los entierros, recordando que el difunto volverá cada año. También acompaña los bautizos, los matrimonios y Ios nacimientos, rememorando las obligaciones para con sus compañeros, hijos y difuntos. El bailetambién "es para estar juntos", significa la al egría y la convivencia con toda la familia. Está relacionado con el ave, porque ella canta y chilla, reconoce al macho y la hembra, se mueve y está alegre. "Por eso los mayores dicen que así mismo tiene que estar, en vez de estar Ilorando" (taita A belino Dagua, 2002). 
Indudablemente, las iglesias protestantes han entrado en franca lucha con estetipo de prácticas queconsideran incitaciones satánicas, o por lo menos inconvenientes cristianos. Para los miembros de la Alianza Cristiana, Torre Fuertey otras iglesias no muy restrictivas, la cultura guambiana es un aspecto valioso que sin embargo se piensa en términos críticos y hasta negativos. Consideran que al mezclarse con la práctica católica, y al introducir al cohol einvolucrar excesos en las fiestas, la cultura guambiana perdió su sentido e, incluso, es imposible recuperarla. Para los grupos más restrictivos, como Bethesda, el Movimiento Misionero Mundial o las Iglesias Pentecostal y Pentecostés, la cultura guambiana es una pesada carga de tradición vinculada al pecado y las fuerzas malignas. Tal como explica Trino Cuchillo (2002), "la tradición es anatema y ¿qué es anatema? Pecado".

De este pensamiento, ya sea que ejerza crítica o satanización, se desprende el abandono de algunas prácticas culturales como la música y el baile, pues se piensa que las fiestas, junto a la música no cristiana, los bailes y el alcohol, traen perversión y problemas al ser humano. Por esto, los protestantes han cambiado los ritmos del tambor tocado a cuatro manos y las armonías con melodías de flauta, por arreglos de guitarras, panderetas, tambores y arreglos corales cristianos. Estos cantos son extraídos de himnarios protestantes o han sido creados a ritmos de baladas, rancheras y canciones andinas. A diferencia de algunas comunidades paeces que insertaron la música tradicional al culto evangélico, en Guambía la música se mantuvo ajena a los cambios y las transformaciones de las nuevas religiosidades.

No obstante, en otro campo simbólico, algunas de las concepciones protestantes asociadas a la muerte han encontrado puntos de enlace con los pensamientos guambianos. Un ejemplo de esto es la ausencia de la finalización de la existencia del difunto en el momento desu funeral. Su existencia inmaterial y su posible retorno se evidencian tanto en el Kansrè (Vasco, et al., 1998), un mundo destinado al camino emprendido por los muertos en el pensamiento guambiano, como en la idea cristiana, fuertemente sostenida por el protestantismo, de la resurrección de los muertos.

Por su parte, ninguna de estas relaciones culturales han causado tantos choques y reacciones como el pensar en el versículo de 
Deuteronomio 22:5, según el cual hombres y mujeres deben vestir diferente. Este versículo ha implicado la defensa del anaco tradicional de las mujeres en contra del uso del pantalón, pero también ha cuestionado el uso del rebozo o la fal da de los hombres guambianos.

Para los testigos de Jehová, una de las iglesias más restrictivas de la región, el vestido guambiano no representa ningún peligro simbólico, pues a diferencia de la falda escocesa, dicen ellos, el vestido guambiano no implica manifestaciones nacional istas o fetichistas. En efecto, el vestido indígena no pretendeser un elemento quelos separe políticamente del Estado o deDios, pero es un eje identitario a través del cual se establece claramente la diferenciación social y se exterioriza una pertenencia construida histórica y políticamente. Lo que para los testigos de Jehová se convertía tan sólo en un exotismo local, para los guambianos era una lucha simbólica y política clara.

No obstante, al gunos creyentes y movimientos religiosos no estaban deacuerdo en dejar a los hombres la elección de su vestido. Trino Cuchillo, líder dela Iglesia Pentecostal Unida de Colombia, defiende abiertamentela pérdida del vestido tradicional. Sin embargo, su posición cultural mente restrictiva se contrarresta al pensarse a sí mismo como un gran conocedor dehistorias y vivencias en torno a seres como el Pishimisak-Kallim y como un guambiano que sabe de la Guambía de los páramos. Por su parte, los miembros de Bettesda, aunque fundamentalistas y severos en su mensaje doctrinal y político, defendieron reciamenteel vestido tradicional. Algunos más, como loslíderes delaA lianza Cristiana y la TorreFuerte, defienden desdesusiglesiasel uso dela lengua y el vestido, y el respeto por la música y los mèrèpik.

Evidentemente, la renovación permanente de las prácticas y las adhesiones étnicas generaron múlti ples transformaciones y recreaciones rituales. A diferencia dela sumisión política al cabildo indígena y dela valoración de la lengua propia, los el ementos de participación y distinción simbólica y cultural circularon en forma dinámica. En medio de esta circulación, el ementos como la música y la danza semantienen casi infranqueables, a pesar de que elementos como las concepciones de la muerte física evocan recuerdos y afinidades. Por supuesto, todos los elementos de participación ritual y de memoria cultural están dispuestos al choque, a la negociación y al cambio. El 
vestido tradicional, las prácticas médicas y la mitología territorial discurren entre olvidos y recuerdos, entre reivindicaciones y ausencias, que negocian frecuentemente los elementos y las prácticas que hacen partícipes a los creyentes de la comunidad original.

Pero estas negociaciones no sól o fueron frentea la cultura tradicional, pues igual de creativo y dinámico fueel enfrentamiento a los postulados misioneros y doctrinales. No podemos olvidar la creación sincrética de nuevas tradiciones culturales protestantes en la antigua I glesia Pentecostal Dios es A mor de Guambía, que surgió como una manera de recuperar tradiciones y costumbres guambianas que estaban perdiéndose y aparecían valiosas a los ojos de los dirigentes de esta disidencia religiosa. Ellos partieron a la recuperación cultural desde la misma cristiandad.

A pesar dequesiempretuvieron en mente un pensamiento negativo de la cultura guambiana, referente a la pérdida cultural de una cierta esencia original de su cultura, utilizaron muchas de las prácticas culturales guambianas y las insertaron en la práctica del protestantismo. Encontraron un anhelo dearmonía y un futuro prometedor, con basetanto en experiencias cultural es ancestral es como en las promesas mesiánicas cristianas. Deesta manera, surgieron la utilización del agua para la sanidad y la mejoría de hombres, animales y cultivos, las ruanas blancas para el culto, las varas de poder, las procesiones a las lagunas, las novedosas danzas y las sugestivas canciones a ritmos de vibrantes tambores. Todas ellas, prácticas que irritaron la generosidad doctrinal de los pentecostales brasileños y cerraron las puertas de un posible enclave misionero.

\section{Cambio, memoria y choque. A manera deconclusión}

Este análisis del impacto cultural y de las transformaciones rituales delos protestantes guambianos ha puesto de relieveel papel dinámico y contemporáneo de los contactos, las imposiciones y las transformaciones étnicas. Sin duda al guna, la idea de "reducir" la diferencia a través de la práctica misionera es uno de los múltiples elementos que intervienen en la relación entre un "nosotros" étnico y un "otros" mayoritario, cada vez menos estático. No obstante, la idea de impo- 
ner se articula con la deadquirir y, evidentemente, el protestantismo y los nuevos y diversos movimientos religiosos forman parte de un universo cultural, simbólico y místico, profundamente atractivo para las subjetividades y colectividades indígenas.

Por supuesto, las transformaciones insertas en este complejo proceso de circulación de la religiosidad guambiana traen consigo frecuentes olvidos, despojos rituales que son vistos como herramientas indispensables de la transformación radical o parcial del creyente ola comunidad étnica en aras de pertenecer al mundo cristiano. No obstante, estas transferencias no se realizan sobre campos vacantes y desolados, sino sobre comunidades étnicas históricamente construidas y densamente ataviadas.

Algunos de estos intereses indígenas estaban anclados en posibles intercambios rituales y conceptuales entre una religiosidad ancestral y el universo protestante, posibles gracias a la existencia de ciertos elementos recurrentes, de espacios previamenterecorridos y detiempos relativamente coincidentes. Algunas piezas del protestantismo, sobre todo de los movimientos cristianos pentecostales y mágicos, se hicieron más o menos habituales a la religiosidad étnica y permitieron tejer algunos vínculos iniciales, con celo perseguidos por el espíritu misionero.

En todo caso, la localización delas transformaciones, los recursosy Ios ideales misioneros indicaron particulares maneras de hallarse en el protestantismo. Las narrativas orales de los creyentes guambianos nos condujeron a través de la trascendencia de la curación, el consejo y las prácticas rituales de los novedosos movimientos. En ellas, las prácticas y preceptos misioneros fueron permanentementecuestionados y la mediación de la religiosidad, el pasado y los recursos rituales previos transformaron voluntaria e involuntariamente la oferta protestante, y significaron permanentes procesos de resistencia y rememoración en medio del cambio.

De la misma manera, la participación vivaz y creativa de algunos de los protestantes indígenas permitió la emergencia de complejas creaciones y transformaciones rituales. En medio defrecuentes y profundas restricciones doctrinales, los creyentes abrieron paso a la creación de vínculos, conscientes o no, entre elementos selectivos tanto de 
la memoria cultural y ritual previa como de las nuevas propuestas adquiridas. Las recreaciones y manipulaciones de grandes órdenes simbólicos concebidos como estructuras antagónicas de la creencia, situó a la memoria y al cambio como elementos dinámicos que intervinieron permanentementeen la dilucidación delas trayectorias dela religiosidad.

Como parte de estas configuraciones, sobre la sabiduría tradicional, el consejo y la palabra delos taitas seejercieron frecuentes renuncias. Lo mismo ocurrió con la música, la danza y la fiesta. En contravía, al gunas delas concepciones sobre la sal ud y la enfermedad, la muerte y la curación, encontraron referentes relativamente reconocidos. Asimismo, las maneras de sanar, aprender, vestirse o sentir el territorio, vincularon prácticas y crearon referentes de una religiosidad inquieta, que muchas veces escapó tanto a los referentes tradicional es como a las orientaciones protestantes.

De una u otra forma, aquellos elementos a través de los cuales se enfrentaban, se comprendían y se manipulaban las nuevas adscripciones religiosas, estaban en directa relación con las tradiciones culturales que sustentaban la pertenencia a una comunidad de origen. Sin duda, las rememoraciones y los olvidos rituales y culturales hicieron parte de una compleja lucha simbólica queincluyó el ementos como el vestido, la medicina, la mitología y la territorialidad. Estos el ementos no se presentan como un cúmulo homogéneo deactitudes y prácticas difícilmente modificables. Todo lo contrario, su existencia, su reproducción o su extravío eran parte de los choques, las tensiones y las pugnas tejidas entre las diversas misiones protestantes, los creyentes y los no creyentes del resguardo. Es evidente que estos elementos aparecen de forma incompleta, repletos de discontinuidades, negaciones y cambios. No obstante, se muestran de manera recurrente e intervienen en la definición de la pertenencia étnica y los referentes culturales compartidos, en medio de la obstinación étnica y el cambio cultural contemporáneo. 


\section{Bibliografía}

Cardoso de Oliveira, Roberto (1992), Etnicidad y estructura social, MéxiCO, CIESAS.

Comaroff, Jean y John Comaroff (1997), Of revelation and revolution.

The dialectics of modernity on a South A frican frontier, Chicago, University of Chicago Press.

Demera, Juan Diego (2004), “Católicos y protestantes entrelos indígenas guambianos. La adopción y transformación de nuevas colectividades", en Juan Diego Demera y Ana María Bidegain, Globalización y diversidad religiosa en Colombia, Bogotá, Unibiblos.

Gros, Christian (1999), "Ser diferente por (para) ser moderno, o las paradojas de la identidad. Algunas reflexiones sobre la construcción de una nueva frontera étnica en America Latina", A nalisis Político, núm. 36, enero de 1999. (2000), Políticas de la etnicidad, Bogotá, ICAN.

Jimeno Santoyo, Myriam y Adolfo Triana, (1985), Estado y minorías etnicas en Colombia, Bogotá, Funcol.

Rappaport, Joanne (1984), "Las misiones protestantes y la resistencia indígena en el sur deColombia", A merica Indígena, 1-44. M éxico.

Rosaldo, Renato (1991), Cultura y verdad. N ueva propuesta de análisis social, México, Grijalbo

Santa, Jairo. (s/ f), Liberación. U n estudio de las prácticas supersticiosas y espiritistas y lo que la Biblia diceacerca de ellas. El cómo ser libre dela posesión de demonios y la manera correcta de consultar con Dios. Mimeo.

Vasco, Luis Guillermo, A belino Dagua y Misael Aranda (1993), “En el segundo día la gente grande (N umisak) sembró las plantas y con ellas bebió el sentido", en Francois Correa, Encrucijadas de Colombia A merindia, Bogotá, ICAN. , A belino Dagua y Misael Aranda (1998), Guambianos: hijos del arco iris y del agua, Bogotá, CEREC. 


\section{Fuentes Orales}

Trino Cuchillo (2002), grabación sonora.

A belino Dagua (2002), grabación sonora y notas manuscritas.

Ignacio Morales (2002), notas manuscritas.

Barbara Muelas (2002), grabación sonora.

A ntonio Pillimué (2002), grabación sonora.

Eulogio Tunubalá (2002), grabación sonora.

Fabio Yalanda (2002), grabación sonora.

Artículo recibido el 18 de mayo de 2005

Artículo aprobado el 21 de octubre de 2005 